\title{
Urbanisation and Energy Crisis: the Case of Lagos State
}

\author{
Lai Olurode', Wakeel Isola ${ }^{2, *}$, Demola Adebisi ${ }^{2}$ \\ ${ }^{1}$ Department of Sociology, Faculty of Social Science, University of Lagos, Lagos State, Nigeria \\ ${ }^{2}$ Department of Economics, Faculty of Social Science, University of Lagos, Lagos State, Nigeria
}

Copyright $\mathrm{O} 2018$ by authors, all rights reserved. Authors agree that this article remains permanently open access under the terms of the Creative Commons Attribution License 4.0 International License

\begin{abstract}
The study employed in-depth interviews to collect information from households living in the upper class areas of Magodo, Lagos and those living in the slum areas of Iwaya. The locations were chosen purposively. The responses from the interviewees indicate that both high and lower neighbourhoods in Lagos experience epileptic power supply and that resident have learnt to cope with the power situation using diverse strategies of coping. The various responding mechanisms adopted by those consumers, however, are based on financial capabilities. From the interviews conducted, it was apparent that both high income and low income families tend towards the use of generators. However, they also make use of lamps and solar energy in few cases. Also, both classes of families use gas stoves as an alternative to electric stoves for cooking. And occasionally they use kerosene stoves. Planning ahead was a recurring feature among the households, which indicated how they prepared for the eventualities of power outages. The study concludes that the way out of the problem is to fully implement the Power Sector Reforms. In addition, there is the urgent need to diversify the sources of generating electricity in Nigeria and mitigate the problem of corruption, which has been the bane of the sector over the years.
\end{abstract}

Keywords Urbanization, Megacity, Epileptic Power Supply, Lagos State

\section{Introduction}

A visit to a typical urban scene in most of the third world countries will bear an eloquent testimony to a breakdown of municipal governance. It is a common experience that frequent power outage, poor road network, slums and mountains of refuse and other signs of urban decay have become the hallmarks of many of these urban cities. In spite of this, migrants have continued to flow in without regard for the huge pressure on infrastructure and social services. That urbanization poses a threat to social services in third world cities is therefore not in doubt.
Perhaps, it is not a mere coincidence that a high rate of urbanization has spurred the development of some megacities across the globe. According to the United Nations [34], there were 31 megacities globally and this number is projected to rise to 41 by 2030 . Of the world's 31 megacities in 2016, 24 are located in the less developed regions. China alone according to this study had six megacities in 2016, while India had five. Africa can only boast of three countries that have attained the status of a megacity namely Kinshasa, Cairo and Lagos. The growth and development of the megacities are expectedly, not without some challenges such as access to electricity, which has been a source of concern in less developed countries.

Legros et al, [16] admit that about 1.5 billion people lack access to electricity in the less developed countries (LDCs). In relation to other regions of the world, the study state that 625 million and 560 million people are without access to modern fuels and electricity in sub-Saharan Africa. It further stated that less than 200 million people in East Asia and the Pacific lack access to electricity.

About $79 \%$ of the people are without electricity access in developing countries. $74 \%$ of them are in sub-Saharan Africa, compared to the $28 \%$ in LDCs. This means that even though access to energy varies widely across LDCs, energy access is far lower in poorer developing countries than in richer ones Legros et al, [16]. The implication of this is also that a large percentage of the population is without access to modern fuels. According to USAEE [32] in 2012, out of the 1.3 billion people who lack access to electricity, over 600 million are in sub-Saharan Africa, while over 300 million come from India alone. However, the World Economic Outlook WEO, [35] maintains that about $16 \%$ of the world population (i.e. 1.2 billion people) lack access to electricity in 2016.

In Nigeria, while electricity access has grown from $27.3 \%$ in 1990 to $57.7 \%$ in 2014 World Bank, [34], the problem of urbanization has continued to play down the impact of such growth over time. Currently, out of the 170 million of Nigeria's population, about 98 million are without access to electricity. The national electrification rate in Nigeria as at the end of 2014 was $45 \%$, out of which urban 
electrification rate was $55 \%$, while rural electrification rate was $36 \%$. Similarly, in terms of biomass for cooking, the population relying on biomass in Nigeria is 134 million; $76 \%$ of this relied on the traditional use of biomass in 2014 WEO [35]. It means that generally in Nigeria, access to modern energy is very low and the energy crisis is very high. The low rate of rural electrification in Nigeria and inaccessibility to modern energy has made the rural-urban migration a necessity and an irresistible trend. This has further exacerbated the problem of urbanization and deepened the energy crisis in the urban areas, especially in Lagos State. Expectedly, the fact that urbanization has occurred arbitrarily in Lagos has exerted a severe strain on existing infrastructure and contributed immensely to energy crisis in the state. Resolving this urban growth problems vis-à-vis those of the energy crisis should be of paramount interest to Nigeria; especially Lagos State. This would help to fast-track the goal of achieving sustainable development in the state and improve the living conditions of the citizenry.

Against this background, this study seeks to evaluate the pushing effects of urbanization and unstable electric power supply on the growth of the Lagos State economy. The motivation for the study stems primarily in the realization that poor electricity supply in the face of a rising urbanization demand could pose a devastating problem on growth. Hence, the need to offer suggestions that can ameliorate the challenges.

The relevant questions this study addresses include: Is there any gap between the secondary energy supply such as, electricity and the requirements of the city? What are the strategies employed to cope with the problem of the electricity gap on the households? These questions will be analyzed within the context of power sector reforms in Nigeria for necessary policy options.

The rest of the study is organized as follows: section 2 presents the stylized facts on the population of Lagos
State and electricity sector in Nigeria, with special reference to Lagos. Review of relevant literature is presented in section 3. Sections 4 and 5 focus on the methodology and results of the study.

\section{Stylized Facts on the Population and Electricity Infrastructure in Lagos State}

Lagos State Population and Trend

Lagos, the $8^{\text {th }}$ largest city in Africa, has continued to experience an unprecedented growth in its population since 1950. The National Bureau of Statistics (NBS) [19] and National Population Commission [20] put the population of Lagos at 325,000 and 8,859,000 in 1950 and 2005, respectively. However, Lagos achieved the status of a mega city in 2010 , with a population of $10,781,000$. It has been projected that by 2030 the population will be about $24,239,000$. This is trend is shown in figure 1 .

\section{Electricity in Nigeria}

The electricity industry began in Nigeria towards the end of the $19^{\text {th }}$ century. The first generating plant was installed in Lagos in 1898 by the colonial government and was managed by the Public Works Department (PWD). In 1950, the government passed the Electricity Corporation of Nigeria Ordinance No. 15. Thereafter, several other legislations were enacted. These include the Niger Dam Authority (NDA) Act of Parliament of 1962 and the Decree 4 of June 1972, by which the National Electric Power Authority (NEPA) was established. NEPA was mandated to maintain an efficient, coordinated and economic system of electricity supply to all parts of Nigeria. The law made NEPA a monopoly by making it the sole body responsible for the generation, transmission, distribution and marketing of electricity.

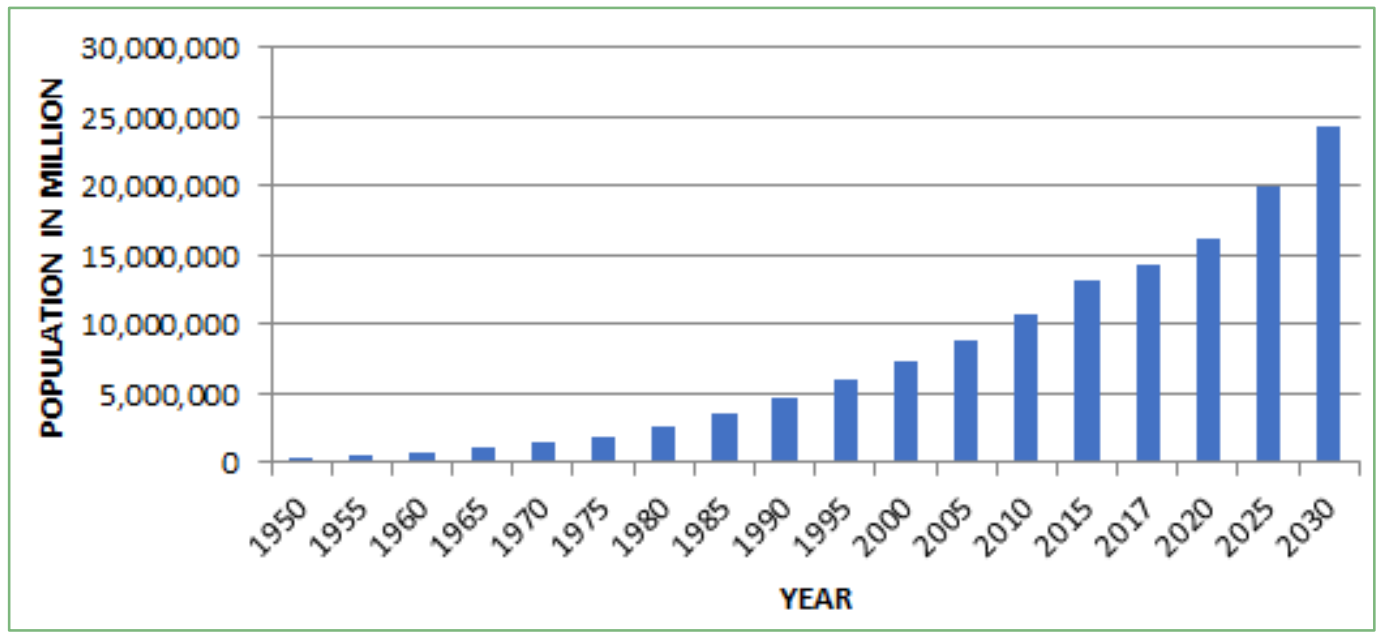

Figure 1. Trend of population of Lagos state 
As a state-owned establishment, NEPA was inefficient in service delivery, innovation and management. In an effort to reverse the poor electricity tale, the government decided in 2000 to embark on a comprehensive review of the sector, in terms of policy and institutional reforms. NEPA and its successor company, the Power Holding Company was corporatized and commercialized and this enabled the organization to review its tariffs upward without an appreciable increase in quantum of electricity generation. The most radical change came with the passage of the Electric Power Sector Reform Act (EPSRA) in 2005 which made Nigeria to effectively join the global restructuring and deregulation trend. Under the reform, NEPA/PHC was broken into 18 companies, comprising 6 generators, 11 distributors and one transmission company. In addition, the deregulation of the sector again opened up the market for the Independent Power Producers and other private initiatives by other stakeholders including state governments, such as Lagos State.

\section{Current Situation with Lagos State Electricity}

Lagos State is the only Nigerian state with a very aggressive Ministry of Energy and Mineral Resources. The establishment of this ministry was borne out of the fact that the Lagos State Government has in recent times embarked on several energy-related projects which range from Independent Power Plants to Solar Energy Projects and to Public Lighting largely inspired by the power sector reform. It also covers Household energy and emissions calculators Lagos State Electricity Board [14]. The Independent Power Plants (IPPs) set up by the State are designed to improve electricity access by taking the state off the national grid. The State previously operated 3 IPPs at Akute, Lagos Island and Alausa. It has so far installed $32.55 \mathrm{MW}$, connected to more than 50 load centers and supplied over $70 \mathrm{KM}$ of public lighting. According to the Lagos State Electricity Board, the IPPs have helped to drastically improve the electricity supply reliability from $30 \%$ to about
$99 \%$ on the average, making them more effective in providing better service to the populace. The State also currently has two additional IPPs: the Mainland Power and the Peninsula Integrated Power Project. The two IPPs have a combined capacity $14.8 \mathrm{MW}$. To ensure that the State sustains and improves on its present energy supply condition, it embarks on a state-wide energy audit with the aim of collating a comprehensive database of the real-time power demand of Lagosians and that of the installed capacity from the grid. Consequently, over 13,000 residential, industrial and commercial locations were audited at the end of 2013 and the exercise revealed that only a little above $10 \%$ of electricity demand by the state was met by the national grid. The state discovered over 17,000 generators in the audited locations, meaning that each location has at least 1 generator. This translated to the consumption of about 162,000 litres of diesel per day and resulted in about $178 \mathrm{lbs}$ carbon emission per day. In order to curb the volume of emissions arising from electricity consumption in the metropolis, the Lagos State Electricity Board (LSEB) recently took a stand in favor of renewable energy. The office of the LSEB in Ikeja currently generates about $70 \%$ of its energy from a $12 \mathrm{kWp}$ Solar farm installed within its premises LSEB, [15].

Nigeria only generates less than $5000 \mathrm{MW}$ for a population of 170 million. Incidentally, Lagos State accounts for $40 \%$ of the total electric supply for industrial, commercial and domestic demands as characterized by the power supply companies, thus highlighting the picture of the problem. For example, in 2013, the demand for electricity was approximately 5000MW in the Eko Disco Zone alone Eko Disco [5]. In 2011, the distribution capacity of both Ikeja and Eko Discos was put at 854MW and 796MW respectively, giving a combined total of $1650 \mathrm{MW}$. Also, the customer population of each of the Discos was put at 658, 701 and 286, 758 respectively The Nigeria Energy Support Programme (NESP) [30]. A summary of this picture is depicted in table 1.

Table 1. ELECTRICITY SUPPLY GAP in LAGOS STATE in Megawatts (MW)

\begin{tabular}{|l|l|l|l|l|l|}
\hline Year & $\begin{array}{l}\text { Electricity demand Ikeja } \\
\text { DISCO (MW) }\end{array}$ & $\begin{array}{l}\text { Electricity demand Eko } \\
\text { DISCO (MW) }\end{array}$ & Total estimated & Total supply by & Electricity \\
DISCOS (MW) & gap/crisis \\
Ikeja and Eko \\
(MJW)
\end{tabular}

Source: Nigeria Energy Support Programme (2015) and own computation. DC (Distribution Capacity). MW (megawatts). 


\section{Literature Review}

The relationship between urbanization and energy related crisis has received a scholarly attention in the literature. Parikh and Shukla [23] examined the role of urbanization, energy consumption and green-house emissions in economic development. The study employed a multiple regression framework using a cross section of data to analyze the indicators of urbanization and other economic indicators. It was observed that aggregate energy consumption increases with urbanization. By the same token, Shahbaz and Lean [25] analyzed the relationship among urbanization, industrialization and energy consumption in Tunisia between 1971 and 2008. It employed the autoregressive distributed lag (ARDL) bounds testing approach as well as the Granger causality tests to analyze the secondary data which cover the variables of interest. Findings from the study suggest that a bidirectional causality exists between industrialization and energy consumption. Additionally, it was observed that urbanization intensified the volume of energy consumption in Tunisia over the period studied. The study, thus, called for the examination of the nexus between industrialization and urbanization to fast-track the development process. Similarly, Shen et al [26] investigated the relationship among urbanization, sustainability and energy utilization in China. In the study, the trend among the variables was analyzed and it was observed that a positive relationship between growth, urbanization and energy demand in China existed. The study therefore concluded that if urbanization grows faster than predicted, China might face a long term resource shortage. In the same vein, Wang [33] analyzed the impact of urbanization on China's energy consumption. The study defined two types of energy use in the urbanization process as residential energy consumption (REC) and production energy consumption (PEC), observing however that growth enhanced by urbanization increased REC while PEC was consistently reduced between 2001 and 2005 in China.

Certain other studies have also focused on the correlation between urbanization and energy consumption, where it was observed that a positive relationship exists between urbanization and energy use. For instance, Jones [13] conducted a cross-sectional study on 59 LDCs and observed that urbanization significantly increased energy use. Imai [9] empirically observed that urbanization contributed to energy crisis in China. Zhou et al [36] identified and analyzed three energy-consuming sectors that are strongly linked with urbanization as residential, industry and transportation. The study fundamentally observed a negative relationship between energy demand and urbanization. Ewing and Rong [6] observed that more urban areas had very reduced energy consumption per-capita in Canada. Similarly, other studies have focused on the causal link between urbanization and energy consumption. A study by Liu [17] revealed that urbanization has a positive causal effect on energy consumption in China. Fan and Xia [7] found out the same results in China. Mishra et al [18] observed that short term causality exists between energy consumption and urbanization in the Pacific Island Countries. In another study by Halicioglu [8], it was observed that causality runs from prices, urbanization and GDP to energy consumption in Turkey between 1968 and 2005.

World Bank [34] report on African urbanization revealed that African countries lag behind their peers in developing countries in terms of infrastructure provision. Access to electricity reaches only 16 percent of African citizens, when compared with the 41 percent in other developing countries. Average power consumption is 124 kilowatts per capita, or 10 percent of that in the rest of the developing world. African firms report losing 5 percent of their sales because of frequent outages. This figure jumps to 20 percent for informal firms. While private firms are eager to explore the potential of African growing markets, lack of infrastructure constitute major obstacles to private investment.

According to Arnulf and Jayant [1], rapid migration and natural population growth in cities can overwhelm the provision of basic urban services, particularly for the poor urban dwellers. Several hundred million urbanites in low and middle income nations lack access to electricity and are unable to afford cleaner, safer fuels, which result in-significant adverse consequences for human health and local air quality.

Supporting Sub-Saharan African Municipalities with Sustainable Energy Transitions SAMSET [28] showed that total population in South Africa is growing at 1 percent per annum. The population is predominantly urban, and currently 64 percent of the approximately 52 million total population live in towns or cities, of which 40 percent are located in the large metros. This is expected to increase to 70 percent by 2030 . Cities and towns produce 80 percent of South Africa's Gross Value Added (GVA), and home to around two-thirds of the population. With the predominantly urban growth, South Africa has not been able to address the challenges of poverty levels substantially. The main energy dimensions of this include thermally uncomfortable housing and lack of access to modern affordable energy sources. Poor households spend 14 percent, on average, of their income on basic energy needs, as opposed to 2 or 3 percent for wealthier households. In South Africa, the modern energy focus has been on electricity provision. The report also showed that national electrification rate levels are 87 percent when compared to 36 percent in 1994. However, a significant number of households remain without electricity connection. The current electrification backlog is 1.2 million for the informal and 2.1 million formal households.

Simon and Innocent [27], in their review of literature of the nexus between urbanization and energy demand in Ghana revealed that energy for lighting in urban Ghana is 
predominantly electricity. Though available to all urban dwellers, it is inaccessible to urban poor who still depend on candles for lighting or get connected illegally from their neighbours. The supply of electric power is also very unreliable, marked by persistent power fluctuations and blackouts. As a result of this, many people have resorted to the use of diesel generators, with high pollution levels, to satisfy their energy electricity needs.

In terms of studies in Nigeria, Babanyara and Saleh [2] focused on urbanization and fuel wood usage as a source of energy in Nigeria between 1990 and 2000. Fuel price hikes, rural-urban migration and urbanization were identified as the major factors causing fuel wood energy demand in Nigeria. It was also confirmed that the country lost an annual average of 409,700 hectares of forest to urbanization. It then recommended the harnessing of renewable energy sources as a panacea for reducing the consumption rate of fuel wood in Nigeria. Jiboye [12] examined the issues and challenges involved in effective urban governance in Nigeria. Three major issues of sustainable development and governance, urbanization challenges and the necessity for effectively managing sustainable urbanization were addressed in the study. It was observed that the pervasiveness of urban growth in Nigeria has a strong link to globalization, population explosion and industrialization. It therefore called for a participatory and collaborative effort in addressing urbanization crisis.

The Economic Commission for Africa (ECA) [4], in its report on urbanization across cities in the world showed that Lagos is Nigeria's richest state, producing about $\$ 90$ billion a year in goods and services, making its economy bigger than that of most African countries, including Ghana and Kenya. In terms of population, it adds 600,000 people annually to Nigeria's population. The report concluded that a fastest growing state like Lagos without commensurate improvements in social services has pushed Lagos to its cliff edge.

According to a report on the energy sector in Lagos conducted by Department for International Development (DFID) [3], Lagos was identified as a megacity of over 20 million people and as the economic capital of Nigeria. Its rapid growth places pressure on resources and the ecosystem to the extent that these services could not support the needs of its citizens. The report also presented a stylized fact about the energy situation in Lagos State. The report showed that; (1) power deficit in Lagos equal $9,000-10,000 \mathrm{MW}$ and low utilization of generating capacity; (2) $40 \%$ of the population has no access to the electricity grid and inadequate transmission capacity; (3) $150 \mathrm{kWh} / \mathrm{yr}$. average annual consumption; (4) $80 \%$ of the population relying on diesel generators; (5) governance challenges federal-state ownership of management of assets; (6) minimal renewable energy in Lagos energy mix and; (7) fossil fuel subsidies in place.

The risk factors facing the Lagos energy- electricity sector are highlighted in the report. The report showed that: (1) 30 million people will be residing in Lagos in 2030; (2) 200,000 engineers will be required for the energy sector over the next 15 years; (3) $\$ 14$ to $\$ 33$ billion is required to fund investment in energy-electricity generation by 2030 depending on technology; (4) 200MW new generation capacity will be required for planned mass transit infrastructure and; (5) 16,000 to $27,000 \mathrm{MW}$ of new generation capacity will be required in 2030 .

The potential interventions as shown in the report included: (1) development of offshore gas; (2) embedded generation-independent power plant (conventional and renewable); (3) municipal energy fund to finance rural and urban solar projects; (4) community biogas project; (5) offshore wind; (6) compressed natural gas transportation; (6) promotion of energy efficient appliances and; (7) building regulation.

From the stylized facts on the Lagos energy sector, this study aims to carry out a pilot study of the nexus between urbanization and electricity crisis in Lagos, with a view to revealing and understanding the severity of the electricity crisis in the state. The benefit of this pilot study is that it gives a glimpse of what the bigger picture might look like.

\section{Methods}

To arrive an in-depth understanding of the coping strategies of Lagos residents to the epileptic power supply, two households with differing social status were interviewed. The first household was chosen from the upper class areas of Magodo, Lagos. The household include a family of five who live in a duplex while the other household was selected from the slum areas of Iwaya, Yaba, Lagos, which is a family of seven living in a single room apartment In choosing the representative sample, a random sampling method was adopted.

The following processes were involved in the final section procedure for the household in Magodo area. (i) Certain criteria were laid out, which include that the housing must be a Duplex, with fence all rounds. Also there was a security by the Gate side. (2) The addresses of the duplex were taken. (3) The Chairman of the Landlord Association was contacted first. (4) The purpose of the exercise was well communicated to each and every landlord after a formal letter soliciting for their cooperation were served to each of them. (5) The purpose of the exercise was communicated to each participant before the day. (6) A piece of paper which carried a "yes" or "no" of addresses of the participants was shuffled and whichever option came up would serve as a representative for the assignment.

The same procedure was carried out in Iwaya, Yaba corridor/axis except that the assumption of being a duplex with fence and security gate was ruled out. The sample, to a very large extent, appeared as a true reflection of the 
population of households in Nigeria, thus exhibiting the rich and poor dichotomy. In addition, a case study illustrating a typical day in the life of an average Lagos state resident was discussed.

The locations were chosen purposively. The intention was to select two households with differing social class and status, in order to understand their experiences and coping strategies with the power situation in Lagos. Magodo is known to be a highbrow area in Lagos while Iwaya is one of the lower class neighbourhoods in Lagos. In the course of this discussion the household from Magodo will be referred to as Household A (HHA) and the household from Iwaya will be referred to as Household B (HHB). The research methodology employed in this work has been extensively used in the analysis of other related social economic issues (see for example, Olurode, [21], [22] and Tade [29] among others.

In spite of the differing social class and status of the two households focused in this study, the interview revealed that the coping strategies adopted by them were similar but different in terms of intensity and amount. This will be discussed accordingly in the subsequent headings.

\section{Results and Discussion of Findings}

\section{Regularity of Power Supply}

In discussing the frequency, duration and stability of power supply in Lagos, the two households though in opposite ends of the city, claimed that power supply has been much better of late. They stated that unlike previous experiences when there could be no power supply for two to three days consecutively (and in extreme cases for weeks) electricity supply has become much better because they now enjoy better power supply. Upon further probing, the interviewer noted that the 'better power supply' the consumers alluded to could be for a period of 12 hours in a day. In their words:

\section{"if I had probably had this interview a month ago, I would have said power supply is really bad however, of recent we've been enjoying better power supply, We have light at night and during the day, at night from like 8 till 8 the following morning and then maybe they'll now bring light at around like 12 till 2, then 8 again till 8 again the next morning...” (IDI, HHA) \\ "For now the power supply is very stable unlike before, because whenever I get home, I find out that there's light, there's light, so most of the things we are able to do it with electricity" (IDI, HHB)}

Even though the above account suggests that the power situation might have somewhat improved in Lagos, respondents also noted the problems in the quality and distribution of power.
“...But about a month ago, we hardly use to have power from Disco... and now that there is light, sometimes it is not usually enough to power all the appliances in the house, I don't understand but its like the power is not distributed evenly. Downstairs light is full while upstairs is not at all, while all the sockets downstairs are working, all the lights are working, those upstairs will not and because we can't put on the generator when there's light we make use of torches and lamps..." (IDI, HHA)

\section{Alternative Source of Power}

Many residents of Lagos are unable to rely solely on the national grid power supply from the Discos. This is as a result of previous experiences of unsteady public power supply. Many, therefore, resort to using an alternative source for themselves. In the two households interviewed, alternative source of power ranged from the use of industrial generators, to the smaller sized generators (popularly known as 'I pass my neighbour') and even to the use of electric charged lamps, solar charged lamps, electric charged torches and Kerosene lanterns. In the words of one of the respondents:

"We rely on generators at night, and if there is no
diesel for the generator, we have charged
torchlights that we use, and in the mornings we
rarely put on the generator, we make use of the
charged lamps and torchlights and at night, we put
on the generator from 7 till 10pm max" (IDI, HHA)

It is also important to mention that although none of the households make use of inverters or solar energy as alternative sources of power, they mentioned having knowledge of neighbours and friends who have such experiences. This point to the fact that inverters and solar energy are also popular means of generating power among the residents in Lagos.

"I even know people who solely rely on solar energy, they don't bother with Discos anymore" (IDI, HHA)

And although Kerosene lanterns are not as common as it was before, it is still commonly used among the lower income families. The respondents from Iwaya mentioned that kerosene lanterns are among their major source of light.

'We have a kerosene lamp in the kitchen, which we use while cooking (IDI, HHB)

Not too surprising, the respondent from Magodo felt it was archaic and outdated to use kerosene lamps. In their opinion:

"Kerosene lamps? No, not at all, that's like from the 19th century" (IDI, HHA) 


\section{Dealing with Cooking and Other Domestic Tasks}

Owing to the high rate of urbanization in Lagos, many residents have abandoned the traditional ways of cooking, carrying out house chores using more modern methods. Instead of the use of charcoals and firewood (which are still very common in rural areas) residents of Lagos prefer the use electric appliances such as electric cookers, electric irons and so on. This might partly be due to the fact that electrical appliances are better suited to an urban area as they are more space efficient. However, the epileptic power a supply has resulted in residents seeking alternative ways of executing their domestic chores. It is often common experience that residents experience electricity power disruption, in the middle of their cooking which makes looking for alternative sources of power imperative for them. From the interview, it was gathered that the most common alternatives sought after were gas cookers and kerosene stoves for cooking, and for other domestic chores such as ironing. These alternatives have been used as rescues whenever there was power supply disruption. In the words of the respondents:

"we iron our clothes beforehand, then for washing, we make use of the dry cleaner. We have washing machine, but we rarely use it because of the power situation, so what we do is we pile up the clothes until there is light, although we kind of make our plans separate from the possibility of power supply from Disco, we really don't rely on Disco" (IDI, HHA)

"We don't store foods as much, because of the unstable power supply, because we might not have light for like two three days, we hardly use the Mikano, it's the small gen we use often and that one cannot carry the freezer, so we hardly buy food in bulk to store. So what we do is buy what we can eat within a short period of time”. (IDI, HHA)

"to generate water, we often have to use the pumping machine to pump water, and for that we need to put on the mikano gen...but if there's no diesel we either use Meruwa (water sellers) or go fetch water from a neighbouring house" (IDI, HHA)

"To grind pepper I have to use local grinder, the stone grinder which makes it very difficult unlike if there's electricity, I can use the electric blender which makes it easier" (IDI, HHB)

"To straighten our clothes when there is no light, we fold and put under the pillow or sometimes we can take it to somewhere there is light to iron, we also take chargeable things like phone, torch to charge and pay a token sum to get them charged" (IDI, HHB)

\section{A Day in the Life of an Average Lagos State Resident}

An average resident lives far away from the place of work, thus he has to wake up at 5.00 a.m. or thereabout. His/her travels time to work would be some two hours to his/her place of residence. However, while he/she is planning to get his/her clothes ready, public power supply goes off. Upon waking up, he rushes his prayers, quickly gets hold of the pressing iron to complete the exercise. His plan to leave the house by 6.15 a.m. has to be given up. Public power went off before he could complete the ironing. Attempts to put his power generator (popularly called I pass my neighbour) is frustrated. There is not enough fuel in the generator and the plug looks bad.

Having given up on ironing, he rushes out to the bus stop to meet a long queue. Of course, he makes it late to work but much before his boss could arrive. But the line has been drawn. Upon getting inside his office, he quickly charges his phone which had run out of power. He also has enough time to boil water to make tea as he could not make breakfast before leaving the house. A day or two before he had thrown away all the fruits and food in his freezer. They had gone bad because of epileptic power supply.

But our average resident is having a sigh of relief as additional hours are being added to public power supply. He now spends less diesel and petrol. But still, he is unable to plan as constant public power supply cannot be guaranteed. For the most part, he has to contend with 'never expect power always' - a sad commentary on the acronym of the old agency saddled with public power supply - NEPA.

At his backyard, the Lagos resident would have some disused generators - a junk backyard of a sort. Not a small percentage of his monthly income is spent on diesel or petrol purchase. He has to sleep most night without public power supply. Whenever the weather is unfriendly, he is forced to sleep in the open, not minding severe mosquito bite, which makes many vulnerable to malaria - a killer disease.

\section{Conclusions}

An assessment of the reliability of power supply in Lagos State shows that all the respondents agreed to the relative stability of electricity, which has made them to enjoy their electricity-powered appliances. This is a pointer to the fact that time dimension is an important factor when assessing the reliability of electricity supply in Nigeria. In fact, electricity is more stable during the rainy season in Nigeria. During this period, hydro power Stations generate optimally, with attendant positive effects on the quantum of electricity supply in Nigeria. In other words, the various efforts of the Lagos State government to boost power supply in Lagos has been complemented by the climatic factor. The implication of this is that there is a need to ensure an appropriate energy mix in the generation 
of electricity in Nigeria. This argument has been extensively discussed elsewhere; see for example Isola [10] and [11]. There is no doubt that the quantum of electricity generated in Nigeria is still very low. A comparative analysis of Nigeria with her supposed counterparts the United Energy Information Agency data is able to show that in 2016 the install generating capacity in Brazil was 150,000 megawatts; Similarly, South Africa generated 42,000 MW; while Egypt generated 33,000 MW. Nigeria's installed capacity is $6,953 \mathrm{MW}$, but highest daily output in October, 2017 was about 4,600 Mw. This is considered too dismal for an economy which experts say needs a minimum of $44,000 \mathrm{MW}$. Perhaps it has become necessary to take a cue from other countries such as Peru, Argentina and Chile where the privatization of power infrastructure has been effective. In Argentina for instance, power generation post-privatization rose from about 12,000 MW in 1992 to about $23,000 \mathrm{MW}$ in 2002. The reverse is the case in Nigeria, which explains the high electricity supply gap in Lagos State. This also explains the need to revisit the privatization process of the DisCos and the GenCos. This will be to ensure and appreciate the beauty of transferring of government companies to the private sector as it was done to the Telecommunication Industry.

Finally, the responses from the interviewees indicate that both high and lower neighbourhoods in Lagos experience unstable epileptic power supply and that resident have learnt to cope and adapt with the power situation using diverse strategies of coping. The coping mechanisms, however, are based on financial capabilities. From the interviews, it was apparent that both high income and low income families tend towards the use of generators. However, they also make use of lamps and solar energy in few cases. Both classes of families also use gas stoves as an alternative to electric stoves for cooking and occasionally they use kerosene stoves. Planning ahead was also a recurring feature among the households and families, which indicated how they prepared for the possibility of power outage. Planning ahead is thus part of the respondents' coping mechanisms. The way out of the problem is to fully implement the Power Sector Reform. This is capable of providing an efficient supply of power in the urban cities and rural areas. More importantly, this can be achieved through the rural electrification initiatives.

\section{REFERENCES}

[1] Arnulf, G., \& Jayant S. (2015). Urban Energy System. International Institute for Applied Systems Analysis, Austria and Yale University, U.S.A.

[2] Babanyara, Y. Y., \& Saleh, U. F. (2010). Urbanisation and the Choice of Fuel Wood as a Source of Energy in Nigeria. Journal of Human Ecology, 31(1), 19-26.

[3] Department for International Development (DFID, 2014).
Future proofing cities: The Lagos Energy Sector (Risk and opportunities for resilient growth of the Lagos energy sector). Atkins Limited.

[4] Economic Commission for Africa (ECA, 2016). Report on urbanization across cities in the world: Africa's cities of the future. Available at www.un.or/africarenewal/magazine/april- 2016.

[5] Eko Electricity Distribution Company (2014). Preliminary challenges and outlook for power distribution in Nigeria. EKEDC, March, 2014.

[6] Ewing, R., \& Rong, F. (2008). The impact of urban form on US residential energy use. Housing policy debate, 19(1), $1-30$.

[7] Fan, Y., \& Xia, Y. (2012). Exploring energy consumption and demand in China. Energy, 40(1), 23-30.

[8] Halicioglu, F. (2007). Residential electricity demand dynamics in Turkey. Energy economics, 29(2), 199-210.

[9] Imai, H. (1997). The effect of urbanization on energy consumption. Journal of Population Problems, 53(2), 43-49.

[10] Isola, W. A (2012) “Towards Appropriate Energy Mix in the Generation of Electricity in Nigeria British Journal of Arts and Social Sciences Vol 6 No 2 pp 224-235 UK

[11] Isola, W. A. (2016) "Power Sector Reforms: Challenges and the Way Forward" Unilag Journal of Humanities Vol 4 No 1 pp 47-163

[12] Jiboye, A. D. (2011). Sustainable urbanization: Issues and challenges for effective urban governance in Nigeria. Journal of Sustainable Development, 4(6), 211-224.

[13] Jones, D. W. (1989). Urbanization and energy use in economic development. The Energy Journal, 10(1), 29-44.

[14] Lagos State Electricity Board (2013). Lagos state government energy sector projects, (September 2013).

[15] Lagos State Electricity Board (2015). Lagos state government energy sector projects, (November, 2015).

[16] Legros, G., Havet, I., Bruce, N. and Bonjour, S. (2009). The Energy Access Situation in Developing Countries. United Nations Development Programme, (November 2009).

[17] Liu, Y. (2009). Exploring the relationship between urbanization and energy consumption in China using ARDL (autoregressive distributed lag) and FDM (factor decomposition model). Energy, 34(11), 1846-1854.

[18] Mishra, V., Smyth, R., \& Sharma, S. (2009). The energy-GDP nexus: evidence from a panel of Pacific Island countries. Resource and Energy Economics, 31(3), 210-220.

[19] National Bureau of Statistics (NBS, 2017). Nigeria data and statistics. In world Population Review, 2017.

[20] National Population Commission (NPC, 2017). Lagos state population data. in world Population Review, 2017.

[21] Olurode, O (1986),' Grass Roots Politics, Political Factions and Conflict in Nigeria: The Case of Iwo, 1976-1983' Rural Africana 25-26 113-121 
[22] Olurode, O (1995),' Women in Rural-Urban Migration in the Town of Iwo in Nigeria

[23] Parikh, J., \& Shukla, V. (1995). Urbanization, energy use and greenhouse effects in economic development: Results from a cross-national study of developing countries. Global Environmental Change, 5(2), 87-103.

[24] Salau, T. (2009) Urbanisation and the State of Infrastructure in the Developing World" in Kadiri W. A. (ed.) Our Cities, Our Future: Dialogue on Urban Planning Challenges and Management. Abeokuta: Gbenga Gbesan Associates.

[25] Shahbaz, M., \& Lean, H. H. (2012). Does financial development increase energy consumption? The role of industrialization and urbanization in Tunisia. Energy policy, 40, 473-479.

[26] Shen, L., Cheng, S., Gunson, A. J., \& Wan, H. (2005). Urbanization, sustainability and the utilization of energy and mineral resources in China. Cities, 22(4), 287-302.

[27] Simon B, \& Innocent S.K.A. (2015). The nexus between urbanization and energy in Ghana: A Literature Review. ISSER, University of Ghana.

[28] Supporting Sub-Saharan African municipalities with sustainable energy transitions (SAMSET, 2013). Energy and urbanization in South Africa: context report and literature review. Sustainable energy Africa.

[29] Tade O. (2014). Recruitment and abuse of trafficked children in south - west Nigeria. African Security Review. Available at www.tandfonline.com/loi/rasr20.02 February, 2015

[30] The Nigerian energy support programme (NESP, 2015). The Nigerian energy sector: an overview with a special emphasis on renewable energy, energy efficiency and rural electrification. Deutsche Gesellschaft fur international Zusammenarbeit (GIZ). 2 $2^{\text {nd }}$ Edition, June 2015.

[31] United Nations (2016). The world cities in 2016. Economics and Social Affairs. Data Booklet.

[32] USAEE (2014). 1.3 Billion are Living in the Dark. The Washington Post. https://www.washingtonpost.com/graphics/world/world-wi thout-power/

[33] Wang, Q. (2014). Effects of urbanisation on energy consumption in China. Energy Policy, 65, 332-339.

[34] World Bank (2016). Access to Electricity (\% of population). World Development Indicators http://data.worldbank.org/i ndicator/EG.ELC.ACCS.ZS

[35] World Economic Outlook (2016). Energy Access Database. http://www.worldenergyoutlook.org/resources/energydevel opment/energyaccessdatabase/

[36] Zhou, W., Zhu, B., Chen, D., Griffy-Brown, C., Ma, Y., \& Fei, W. (2012). Energy consumption patterns in the process of China's urbanization. Population and Environment, 33(2-3), 202-220 